main artery is accompanied by abnormalities in the small renal vessels. Because operation entails a high risk for the allograft, one should bear in mind that stenosis may regress spontaneously.

1 Schacht, R A, et al, American fournal of Surgery, 1976, 131, 653.

${ }^{2}$ Smellie, W A B, Vinik, M, and Hume, D M, Surgery, Gynecology and Obstetrics, 1969, 128, 963.

${ }^{3}$ Lindsey, E S, et al, Annals of Surgery, 1975, 181, 604

${ }^{4}$ Doyle, T J, et al, Surgery, 1975, 77, 53.

5 Raphael, M J, et al, British fournal of Radiology, 1969, 42, 873.

(Accepted 8 December 1977)

Department of Internal Medicine, Binnengasthuis, University Hospital of Amsterdam, Netherlands

ANNETTE J VEGTER, MD, senior registrar

E BOSCH, MD, consultant nephrologist

Departments of Roentgenology and Surgery, Wilhelmina Gasthuis, University Hospital of Amsterdam, Netherlands

D WESTRA, MD, professor

H L.INSCHOTEN, MD, chief resident

\section{Prognostic value of the oculovestibular reflex in fulminant hepatic failure}

The mortality rate of patients with fulminant hepatic failure when treated by conservative measures alone is at least $80 \%$. Nevertheless, prediction of the outcome in the individual case is difficult, and, although recent reports have indicated that serum $\alpha$-fetoprotein, $\mathrm{C}^{14}$ cholic acid kinetics, ${ }^{2}$ and the galactosamine elimination test ${ }^{3}$ may be useful, there is some overlap. Serial electroencephalogram monitoring is still probably the most reliable method available but requires specialised personnel and equipment. In the present study changes in the oculovestibular reflex, a simple and easily performed bedside test, were shown to be of equal value.

\section{Patients, methods, and results}

Thirty patients with fulminant hepatic failure with signs of grade IV encephalopathy on admission were investigated (table). In addition to stan dard supportive treatment, three of the patients were treated by repeated daily periods of charcoal haemoperfusion and 17 by polyacrylonitrile haemodialysis. Monitoring of motor responses to compression of dista interphalangeal joints was performed as a means of assessing pain responsiveness. Pupillary light responses and oculocephalic and oculovestibular reflexes (OVR) were performed to assess brain stem function. The oculocephalic reflex was determined by rapid to and fro movements of the head in the vertical and horizontal planes, and the oculovestibular reflex by irrigating the external auditory canal and tympanum with iced water $(20 \mathrm{ml})$.

The oculovestibular reflex was present on admission in 26 patients, and remained throughout the duration of coma in 10 . Nine of the 10 patients recovered consciousness, the other dying from a massive gastrointestinal haemorrhage. Although the OVR was not lost in any of the nine patients, transient losses of motor responses to pain (three patients), pupillary light responses (one), and oculocephalic responses (two) were observed.

Comparison of clinical and laboratory data between the two groups (mean $\pm S D$ )

\begin{tabular}{|c|c|c|c|}
\hline & $\begin{array}{l}\text { Recovery of } \\
\text { consciousness }\end{array}$ & $\begin{array}{l}\text { Non-recovery of } \\
\text { consciousness }\end{array}$ & Significance \\
\hline $\begin{array}{l}\text { Duration of symptoms prior } \\
\text { to admission (days) } \\
\text { Duration of grade IV } \\
\text { encephalopathy (days) } \\
\text { Prothrombin time } \\
\text { (s prolonged) } \\
\text { Albumin (g/l) } \\
\text { Bilirubin ( } \mu \mathrm{mol} / \mathrm{l}) \\
\text { Alkaline phosphatase (IU/l) } \\
\text { Serum aspartate } \\
\text { transaminase (IU } / 1)\end{array}$ & $\begin{aligned} 10 \cdot 1 & \pm 10.9 \\
1.6 & \pm 0.6 \\
88 & \pm 36 \\
32.5 & \pm 9 \cdot 2 \\
230 & \pm 161 \\
146 & \pm 66 \\
1200 & \pm 914\end{aligned}$ & $\begin{array}{c}7 \cdot 7 \pm 7 \cdot 8 \\
1 \cdot 4 \pm 0 \cdot 5 \\
72 . \pm 23 \\
34 \cdot 1 \pm 5 \cdot 1 \\
171 \pm 72 \\
176 \pm 55 \\
1200 \pm 1074\end{array}$ & $\begin{array}{l}\text { NS } \\
\text { NS } \\
\text { NS } \\
\text { NS } \\
\text { NS } \\
\text { NS } \\
\text { NS }\end{array}$ \\
\hline
\end{tabular}

NS $=$ Not significant.
Conversion: SI to traditional units-Bilirubin $1 \mu \mathrm{mol} / 1 \approx 0.058 \mathrm{mg} / 100 \mathrm{ml}$.
The four patients with no OVR on admission died within 2-7 days. Of the 16 patients in whom the reflex subsequently disappeared, 12 died within 1-4 days. In the remaining four patients who also died assessment of the reflex was invalidated by the use of pancuronium during ventilatory support. Of the 20 patients who failed to recover consciousness, positive limb responses to pain in two and positive pupillary light responses in six were observed at some stage during the course of the illness.

Formal 8-channel EEGs were obtained on at least two occasions (total 19) in eight patients. In two of these patients the EEG recordings were persistently isoelectric and the OVR was absent throughout. In two others, cortical activity persisted, the OVR remained throughout, and they recovered consciousness. In the remaining four patients the EEG recordings progressively deteriorated, the OVR disappeared, and the tracings became isoelectric before death. A single EEG recording was obtained in an additional 10 cases. In six, cortical activity was seen at a time when the OVR was present. In two, the readings were isoelectric when the OVR could no longer be obtained. In the remaining two, some activity was present on the EEG recordings at a time when the OVR was absent but both patients died shortly afterwards.

\section{Discussion}

There was no relation between the absence or presence of motor responses to pain, pupillary light responses, and oculocephalic reflexes, and the subsequent recovery of consciousness. In contrast, loss of the oculovestibular reflex in 16 patients was irreversible and all subsequently died. Those who recovered consciousness, however, showed a persistently positive response throughout grade IV encephalopathy. Unlike the biochemical tests referred to in the introduction, the prognostic value of the OVR in fulminant hepatic failure was absolute, and as such its prognostic value appears to be similar in FHF to that reported in head injuries" and "medical" causes of coma such as strokes, uraemia, and encephalitis. ${ }^{5}$ Moreover, the OVR has the advantage over EEG monitoring in that it is a simple and easily performed bedside test requiring less specialised personnel and equipment.

1 Murray-Lyon, I M, et al, Gut, 1976, 17, 576.

2 Horak, W, et al, Gastroenterology, 1976, 71, 809.

${ }^{3}$ Ranek, L, Andreasen, P B, and Tygstrup, N, Gut, 1976, 17, 959.

4 Poulsen, J, and Zilstorff, K, Acta Neurologica Scandinavica, 1972, 48, 282.

5 Caronna, J J, et al, Transactions of the American Neurological Association, $1975,100,25$.

(Accepted 22 December 1977)

Liver Unit, King's College Hospital and Medical School, London SE5 M A HANID, MB, MRCP, research fellow

D B A SILK, MD, MRCP, senior lecturer and consultant physician ROGER WILLIAMS, MD, FRCP, director and consultant physician

\section{Persistent diarrhoea and hypoalbuminaemia associated with cy tomegalovirus enteritis}

Symptomatic cytomegalovirus (CMV) infection restricted to the gastrointestinal tract of adults is uncommon. ${ }^{1}$ It may occur as a primary event or, more usually, as secondary to either a local ${ }^{2}$ or a debilitating systemic disease. ${ }^{3}$ This report describes the occurrence of severe intractable diarrhoea and hypoalbuminaemia with CMV enteritis in a patient with no evidence of pre-existing local or systemic disease.

\section{Case report}

A 68-year-old woman presented, four months before death, with a oneyear history of dysphagia, mild anorexia, weight loss, and more recent onset of diarrhoea. Her health before this had been good. The results of barium swallow, meal, and enema; oesophagogastroscopy; and sigmoidoscopy were normal. Her haemoglobin at this time was also normal. Two months late she complained of increasing diarrhoea, weight loss, and mouth ulcers and was admitted for further investigation. She was pale and thin with angular 
stomatitis and aphthous ulceration of the buccal mucosa. The haemoglobin concentration had now fallen to $9.7 \mathrm{~g} / \mathrm{dl}$; white cell count $4.0 \times 10^{9} / 1$ $\left(4000 / \mathrm{mm}^{3}\right)$; erythrocyte sedimentation rate $125 \mathrm{~mm}$ in the first hour. Concentrations were as follows: serum albumin $17 \mathrm{~g} / 1 ; \mathrm{IgG} 15 \mathrm{~g} / 1 ; \mathrm{IgA} 7 \cdot 4$ $\mathrm{g} / 1$ and $\mathrm{IgM} 0.9 \mathrm{~g} / \mathrm{l}$; serum $B_{12} 455 \mathrm{ng} / 1$; serum folate $1.4 \mu \mathrm{g} / \mathrm{l}$; red cell folate $57 \mu \mathrm{g} / \mathrm{l}$. Autoantibodies were not detected and the results of thyroid function tests were normal. The urine contained only a trace of albumin. Faecal fat excretion was normal, although her dietary fat intake was low at that time. Histologically, a jejunal biopsy specimen showed a trivial degree of villous shortening, consistent with folate deficiency, and a rectal biopsy specimen was normal.

In view of the continued deterioration characterised by persistent diarrhoea and hypoalbuminaemia, empirical treatment with corticotrophin was started two weeks before death. This produced an improvement in her bowel symptoms. Nevertheless, deep leg vein thrombosis supervened, which was treated with heparin, followed by a chest infection that failed to respond to antibiotics. At necropsy bronchopneumonia and small peripheral pulmonary emboli were found. Sections of jejunum showed mucosal ulceration affecting roughly half of the bowel circumference. The ulcers were lined by granulation tissue with an inflammatory infiltrate rich in lymphocytes and plasma cells. Lying apparently within the capillaries of the granulation tissue were many large cells with basophilic cytoplasm and prominent eosinophilic intranuclear inclusions. Such cells had the typical morphological features of $\mathrm{CMV}$ infection (figure). No histological evidence of CMV infection was found in any other organ.

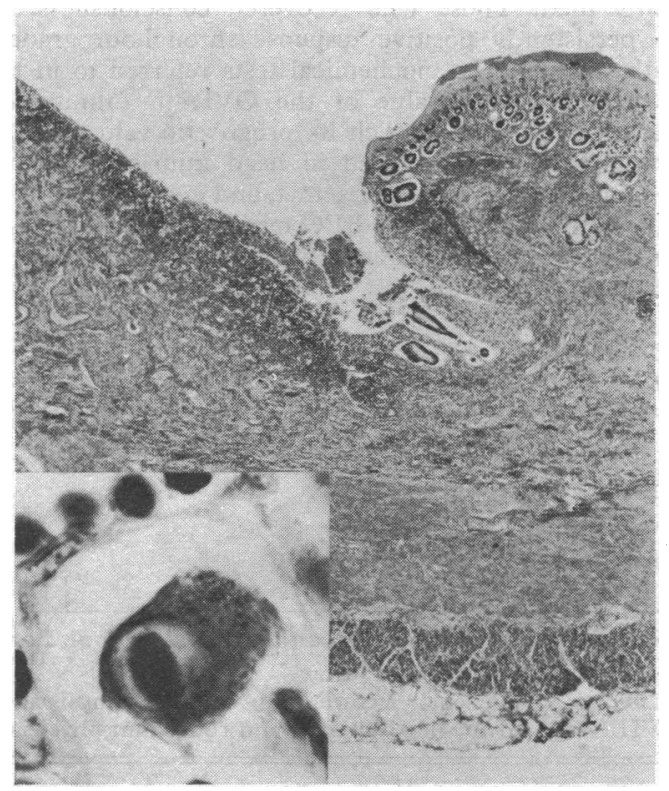

Section of jejunum showing the edge of a mucosal ulcer. The intact mucosa (right) exhibits autolytic changes. Within the capillaries and venules of the granulation tissue in the ulcer are cells showing the characteristic cytomegaly and intranuclear inclusions of CMV infection (inset). (Haematoxylin and eosin. $\times 31$ (inset $\times 772$ ).

\section{Discussion}

Evidence of CMV infection in the gut may be found in either the epithelial cell compartment or, as in the present case, the mucosal and submucosal capillaries and venules. These vascular lesions are associated with mucosal ulceration, presumably owing to local ischaemia. ${ }^{3}$ The lesions, whether epithelial or vascular, are invariably focal and may be missed in intestinal biopsy specimens unless many sections are examined. ${ }^{4}$

Presumably the hypoproteinaemia in this case, in the case reported by Tajima ${ }^{3}$ and in some of the cases described by Levine $e t$ al ${ }^{1}$ reflects serous exudation from the mucosal ulcers in the gut. The severe hypoproteinaemia and diarrhoea in our patient could not be ascribed to any lesion other than that found in the small gut at necropsy. Any causal relationship between the folate deficiency and CMV enteritis in our patient must remain speculative.

CMV enteritis should be considered, therefore, in the differential diagnosis of patients with persistent diarrhoea for which no other explanation can be found-particularly if there is concurrent hypoalbuminaemia. A rising CMV antibody titre may help in establishing the diagnosis during life. Unfortunately, however, this information was not available in the present case.

We thank Dr C D Holdsworth for permission to report this case.

${ }^{1}$ Levine, R S, Warner, N E, and Johnson, C F, Annals of Surgery, 1964, $159,37$.

2 Powell, R D, et al, American fournal of Medicine, 1961, 30, 334.

${ }^{3}$ Tajima, T, Acta Pathologica faponica, 1974, 24, 151.

4 Campbell, D A, et al, Gastroenterology, 1977, 72, 533.

(Accepted 21 December 1977)

University Department of Pathology, Hallamshire Hospital, Sheffield S10 2JF

J C E UNDERWOOD, MD, MRCPATH, senior lecturer and honorary consultant

Royal Infirmary, Sheffield S6 3DA

C L CORBETT, MB, MRCP, senior registrar

\section{Cryptococcosis : survival attributed to combination antifungal treatment}

Cryptococcal meningitis is rare in the UK and occurs mainly as an opportunistic infection. Before the introduction of amphotericin B it was invariably fatal. Flucytosine is also effective in cryptococcal infections. Neither agent used alone is ideal, however, because of non-response, relapse, and toxicity. Medoff et $a l^{1}$ reported in-vitro synergism of amphotericin B and flucytosine against three isolates of Cryptococcus neoformans. The results of treatment in a series of 20 patients were subsequently reported. ${ }^{2}$

We describe a patient who developed cryptococcosis while receiving chemotherapy for Hodgkin's disease. He would probably not have survived without combination antifungal treatment.

\section{Case report}

A 25-year-old plumber was diagnosed in June 1975 as having stage IA lymphocyte-predominant Hodgkin's disease. Staging laparotomy was not performed because he was grossly overweight. He was treated with irradiation directed to the cervical, axillary, and mediastinal lymph nodes, the "mantle" technique being used. By October his health had deteriorated. He had lost weight and developed obstructive jaundice. A lymphogram showed abnormal para-aortic nodes. Chemotherapy was started with the MOPP regimen (mustine, vincristine, procarbazine, and prednisolone). Response was good but halfway through the second cycle he developed acute streptococcal monoarthritis and septicaemia. This responded to benzylpenicillin. One week later he complained of headache and photophobia of sudden onset. Examination showed signs of meningitis. Lumbar puncture yielded purulent cerebrospinal fluid (CSF) under high pressure. Cell count was $145 \times 10^{6} / 1$ $\left(145 / \mathrm{mm}^{3}\right)$, protein $1.53 \mathrm{~g} / \mathrm{l}$, and glucose $0.83 \mathrm{mmol} / 1(15 \mathrm{mg} / 100 \mathrm{ml})$. CSF smears contained yeasts. $C$ neoformans was cultured from CSF and blood. Latex test result for cryptococcal antigen was positive to a titre of $1 / 100$ in CSF and blood. Cryptococcal antibody was not detected.

Flucytosine and amphotericin B were started. Flucytosine was given by mouth, $16 \mathrm{~g}$ daily for four weeks, reducing to $12 \mathrm{~g}$ daily for nine weeks, and amphotericin B by intravenous infusion over six hours. The initial daily dose of amphotericin B $(10 \mathrm{mg})$ was increased by $5 \mathrm{mg}$ a day to a total of $45 \mathrm{mg}$ daily, but at this dose severe rigors occurred. The same dose together with $45 \mathrm{mg}$ hydrocortisone was accordingly given on alternate days and was well tolerated. Over 13 weeks he received a total of $2130 \mathrm{mg}$ amphotericin. The drug was given intrathecally in doses of $0.25 \mathrm{mg}$ and $0.5 \mathrm{mg}$ during the first week, after which CSF smears and cultures remained negative. Three further cycles of chemotherapy were given according to schedule but with prednisolone omitted.

Side effects of treatment were few. Hypokalaemia developed after two weeks but was adequately controlled with potassium supplements or amiloride $10 \mathrm{mg}$ daily. Renal function was otherwise normal. The haemoglobin concentration tended to fall gradually, requiring blood transfusion on two occasions. Serum alkaline phosphatase and $\gamma$-glutamyltransferase concentrations rose three weeks after starting treatment but returned to normal after treatment was stopped. Results of further examinations of CSF during and after treatment were normal.

The patient remained well without any treatment for 18 months. Examination of CSF after 14 months showed a lymphocyte count of $26 \times 10^{6} / 1$ and a protein concentration of $0.81 \mathrm{~g} / \mathrm{l}$, but a search failed to disclose any crypto$\frac{100}{20}$ 